\title{
Efficacy of concurrent treatments in idiopathic pulmonary fibrosis patients with a rapid progression of respiratory failure: an analysis of a national administrative database in Japan
}

\author{
Keishi Oda ${ }^{1}$, Kazuhiro Yatera ${ }^{1 *}$, Yoshihisa Fujino ${ }^{2}$, Hiroshi Ishimoto ${ }^{1,5}$, Hiroyuki Nakao ${ }^{3}$, Tetsuya Hanaka',
} Takaaki Ogoshi ${ }^{1}$, Takashi Kido ${ }^{1}$, Kiyohide Fushimi ${ }^{4}$, Shinya Matsuda ${ }^{2}$ and Hiroshi Mukae ${ }^{1,5}$

\begin{abstract}
Background: Some IPF patients show a rapid progression of respiratory failure. Most patients are treated with high-dose corticosteroids. However, no large clinical studies have investigated the prognosis or efficacy of combined treatments including high-dose corticosteroids in IPF patients with a rapid progression of respiratory failure.

Methods: We enrolled IPF patients who received mechanical ventilation and high-dose corticosteroids between April 2010 and March 2013. Records were extracted from a Japanese nationwide inpatient database. We conducted a retrospective epidemiologic and prognostic analysis.

Results: Two hundred nine patients receiving an average of 12.8 days of ventilatory support were enrolled. There were 138 (66 \%) fatal cases; the median survival was 21 days. The short-term (within 30 days) and long-term (within 90 days) survival rates were 44.6 and $24.6 \%$, respectively. The average monthly admission rate among the IPF patients with the rapid progression of respiratory failure in the winter was significantly higher than that in spring $(p=0.018)$. Survival did not differ to a statistically significant extent in the different geographic areas of Japan. Survivors were significantly younger $(p=0.002)$ with higher rates of mild dyspnea on admission $(p=0.012)$, they more frequently underwent bronchoscopy $(p<0.001)$, and received anticoagulants $(p=0.027)$, co-trimoxazole $(p<0.001)$ and macrolide $(p=0.02)$ more frequently than non-survivors. A multivariate logistic analysis demonstrated that two factors were significantly associated with a poor prognosis: $>80$ years of age $(\mathrm{OR}=2.94,95 \% \mathrm{Cl} 1.044-8.303 ; p=0.041)$ and the intravenous administration of high-dose cyclophosphamide $(\mathrm{OR}=3.17,95 \% \mathrm{Cl} 1.101-9.148 ; p=0.033)$. Undergoing bronchoscopy during intubation (OR $=0.25$, $95 \% \mathrm{Cl} 0.079-0.798 ; p=0.019)$ and the administration of co-trimoxazole $(\mathrm{OR}=0.28,95 \% \mathrm{Cl} 0.132-0.607 ; p=0.001)$ and macrolides $(\mathrm{OR}=0.37,95 \% \mathrm{Cl} 0.155-0.867 ; p=0.033)$ were significantly associated with a good prognosis. The dosage of co-trimoxazole significantly correlated with survival.
\end{abstract}

Conclusions: Co-trimoxazole and macrolides may be a good addition to high-dose corticosteroids in the treatment of IPF patients with a rapid progression of respiratory failure.

Keywords: Acute exacerbation of idiopathic pulmonary fibrosis, Mechanical ventilation, Corticosteroid, Co-trimoxazole, Macrolide, Nationwide database, Acute respiratory failure

\footnotetext{
* Correspondence: yatera@med.uoeh-u.ac.jp

${ }^{1}$ Department of Respiratory Medicine, University of Occupational and

Environmental Health, Japan, 1-1, Iseigaoka, Yahatanishiku, Kitakyushu City,

Fukuoka 807-8555, Japan

Full list of author information is available at the end of the article
} 


\section{Background}

Idiopathic pulmonary fibrosis (IPF) is a progressive parenchymal lung disease with an estimated median survival of 3-5 years from the time of diagnosis $[1,2]$. The disease behavior in patients with IPF is usually diverse, with some IPF patients showing the rapid progression of respiratory failure $[3,4]$. The mortality rate in IPF patients with severe respiratory failure who require a ventilator is around $90 \%$ [5].

Most of the severe IPF patients who show rapid progression of respiratory failure receive high-dose corticosteroids [3, 6]. The 2011 international evidence-based guideline indicates that it as weak positive recommendation [2] in patients with definite or suspected [7] acute exacerbation of IPF (AE-IPF). Thus far, however, there have been no large clinical data sets to investigate the prognosis of patients with AE-IPF who receive ventilator treatment and high-dose corticosteroids. In addition, patients with AE-IPF are pathologically heterogeneous [8], and the appropriate treatment strategy for AE-IPF patients is not fully understood. Recent treatments for patients with AE-IPF include new agents, such as thrombomodulin $[9,10]$ and new ventilator setting strategies that aim to avoid valotrauma $[11,12]$. Such treatments show some promise in their potential to improve the survival rate.

The aim of the present study was to evaluate the epidemiology and prognosis of IPF patients with severe rapid progression of respiratory failure who required ventilator support in Japan, using a large, contemporary, and comprehensive Japanese clinical database, and to explore effective combined treatment options that include the administration of high-dose corticosteroids.

\section{Methods}

\section{Data source}

We used the Japanese Diagnosis Procedure Combination (DPC) database, a nationwide inpatient database, to collect patient data. The details of the DPC inpatient database have been described previously [13]. Briefly, the DPC is a case-mix patient classification system which includes the clinical data and information on the date of admission, the charges, and the quantity of medical care items. The database is linked with a lump-sum per-diem payment system. Data from hospitals including all 82 university hospitals in Japan are gathered and merged into a standardized electronic format by the Japanese Ministry of Health, Labour, and Welfare. The database covers more than 1,500 acute care hospitals located throughout Japan and about 50,000 hospital beds. It represents approximately $50 \%$ of all of the acute care hospitalizations during the same period in Japan. The database includes the main diagnoses, comorbidities present at admission and in-hospital complications as defined in the International Classification of Diseases and Related Health Problems, 10th Revision (ICD-10) codes and text data (in Japanese). The database also includes the following data: patient age and sex; height; body weight; Fletcher, Hugh-Jones (F, H-J) classification; Brinkman Index; drug use; diagnostic and therapeutic procedures; date of admission; length of stay; status at discharge; and the unique identifiers of the hospitals. Attending physicians are obliged to record the diagnoses for each patient at discharge with reference to medical charts to optimize the accuracy of the recorded diagnoses. All of the data were anonymously collected in the database, thus the requirements for informed consent were waived. This study was approved by the Ethics Committee of Tokyo Medical and Dental University, Tokyo, Japan (approval number 788).

\section{Patient selection and data retrieval}

From the total of 39,504 patients who were admitted to the hospitals with a principal diagnosis of other interstitial pulmonary diseases with fibrosis (ICD-10 code J841) and who were discharged between April 2010 and March 2013 patients, we excluded 35,900 patients who did not receive invasive mechanical ventilation within one week after admission because we intended to only evaluate IPF patients with the rapid progression of respiratory failure. Next, non-IPF patients $(n=1,655)$ were excluded based on the text data, followed by patients who were not treated with high-dose corticosteroids (methylprednisolone: $\geq 500 \mathrm{mg}$, daily) within one week after admission $(n=1,740)$. The final study population included 209 patients (Fig. 1). These patients did not include any patients with viral, fungal or infectious bacterial pulmonary diseases as the main diagnosis or as comorbidities at the time of admission.

\section{Definition of variables}

Subjective respiratory symptoms, such as cough and dyspnea, were measured using the F, H-J classification [14]. The institution criteria authorized by The Japanese Respiratory Society were used for defining a respiratory specialized hospital. The seasons on admission were defined as follows: "spring," from March to May; "summer," from June to August; "fall," from September to November; and "winter" from December to February.

\section{Statistical analyses}

A poisson multivariable regression analysis was used to evaluate the differences in the admission rates between the seasons to adjust for the effect of the fiscal year. The chi-squared test or Fisher's exact test were used as appropriate to analyze the differences in the clinical features between survivors and non-survivors. To analyze the prognostic factors for overall survival, a univariate 


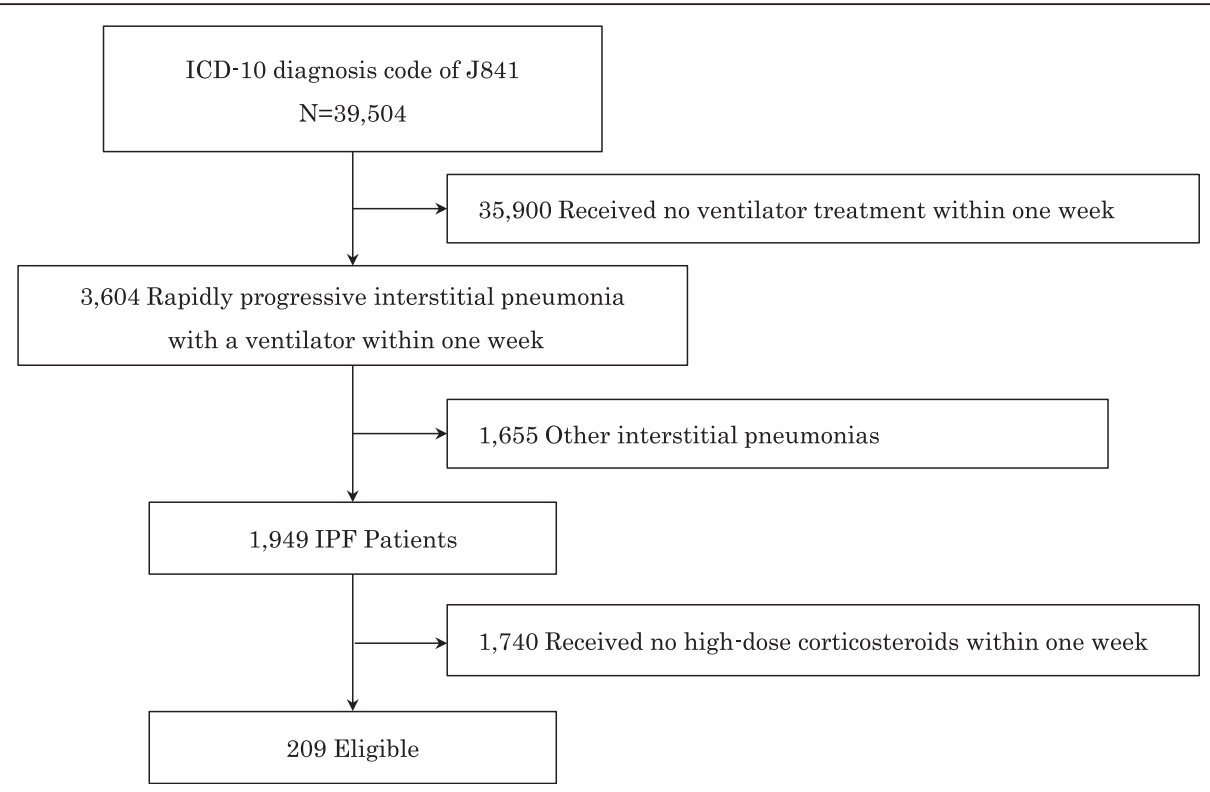

Fig. 1 Sample Selection

logistic regression were initially used to select statistically significant clinical characteristics (sex, age, performing bronchoscopy and an F, H-J classification) and to evaluate each treatment effect (the variables included treatments were applicable at least $10 \%$ of all patients). The final multivariate logistic regression models with backward elimination were also used including the predictors (sex, age, significant clinical characteristics and the treatment). Odds ratios (OR) and $95 \%$ confidence intervals $(\mathrm{CI})$ were calculated. $P$ values of $<0.05$ were considered to be statistically significant. All calculations were performed using the STATA 13 software program (Stata, College Station, TX).

\section{Results}

\section{Patient characteristics}

The clinical characteristics of the patients are shown in Table 1. The mean (standard deviation; SD) age was 72.3 (9.6) years and $82.3 \%$ of the patients were men. The average monthly admission rate among the IPF patients with the rapid progression of respiratory failure in the winter was significantly higher than that in spring ( $p=0.018)$, but was not significantly different to the rates in summer $(p=0.065)$ and fall $(p=0.379)$. The rate of emergent transfer was 48.3 , and $82.8 \%$ of the patients were admitted to specialty hospitals. Ventilatory support was provided for an average of 12.8 days.

\section{Outcome}

The number of patients with fatal outcomes was 138 of 209 (66 \%) during the observation period. The median survival period was approximately 21 days after admission. The short-term (within 30 days) and long-term (within 90 days) survival rates were 44.6 and $24.6 \%$, respectively (Fig. 2). The Hokuriku area had the highest rate of short-term survival (60\%), however, this rate was not significantly different from other areas (Fig. 3). Bronchoscopy and tracheostomy was performed in $20(9.6 \%)$ and $16(7.7 \%)$ patients during hospitalization, respectively. The patient characteristics of the survivors (patients who discharged alive) and the non-survivor (patients who died in the hospital) are summarized in Table 2. The survivors were younger $(p=0.002)$, with mild symptoms of dyspnea on admission $(p=0.012)$, higher rates of bronchoscopy during intubation $(p<0.001)$, anticoagulant (unfractionated and low-molecular-weight heparin) use $(p=0.027)$, cotrimoxazole use $(p<0.001)$ and macrolide use $(p=0.020)$ in comparison to non-survivors. Twenty-seven of 71 (38 \%) survivors who were discharged from the hospitals received home oxygen therapy.

\section{Prognostic factors}

A univariate logistic analysis indicated two significant risk factors for in-hospital mortality: $\geq 80$ years of age $(p=0.033)$ and an F, H-J classification scale of $5(p=$ 0.012), whereas the performance bronchoscopy, and the use of anticoagulants, co-trimoxazole and macrolides were correlated with a good prognosis (Table 3). The multivariate logistic analysis demonstrated that two variables were significantly correlated with inhospital mortality: $\geq 80$ years of age $(p=0.041)$ and 
Table 1 The clinical characteristics of the participants

\begin{tabular}{|c|c|c|}
\hline & $N(\%)$ & Mean \pm SD \\
\hline Patients & 209 & \\
\hline Age, years & 209 & $72.3 \pm 9.6$ \\
\hline$<60$ & $17(8.1)$ & \\
\hline $60-69$ & $52(24.9)$ & \\
\hline $70-79$ & $98(46.9)$ & \\
\hline$\geq 80$ & $42(20.1)$ & \\
\hline Male & $172(82.3)$ & \\
\hline $\mathrm{BMI}, \mathrm{kg} / \mathrm{m}^{2}$ & 178 & $22.3 \pm 3.8$ \\
\hline$<18.5$ & $27(15.2)$ & \\
\hline $18.5-25$ & $114(64.0)$ & \\
\hline$>25$ & $37(20.8)$ & \\
\hline Brinkman Index & 184 & $599.5 \pm 675.7$ \\
\hline 0 & $68(37.0)$ & \\
\hline $1-800$ & $45(24.5)$ & \\
\hline$>800$ & 71 (33.6) & \\
\hline F, H-J Classification scale & 166 & \\
\hline 1 & $2(1.2)$ & \\
\hline 2 & $4(2.4)$ & \\
\hline 3 & $7(4.2)$ & \\
\hline 4 & $28(16.9)$ & \\
\hline 5 & $125(75.3)$ & \\
\hline \multicolumn{3}{|l|}{ Season } \\
\hline Spring & $48(23.0)$ & \\
\hline Summer & $34(16.2)$ & \\
\hline Fall & $56(26.8)$ & \\
\hline Winter & $71(34.0)^{*}$ & \\
\hline \multicolumn{3}{|l|}{ Specialty hospital } \\
\hline Yes/No & $173(82.8) / 36(17.2)$ & \\
\hline \multicolumn{3}{|l|}{ Arrival by ambulance } \\
\hline Yes/No & $101(48.3) / 108(51.7)$ & \\
\hline
\end{tabular}

Abbreviations: $B M I$ body mass index, $F, H-J$ Fletcher, Hugh-Jones. Values are given as mean \pm SD or $\mathrm{n}(\%)$. The total dose was not equal to 209 because there were missing values in the data file. *Significantly different in comparison to spring ( $p=0.018$, poisson regression)

the intravenous administration of high-dose cyclophosphamide ( $\geq 100 \mathrm{mg}$, daily) $(p=0.033)$. In contrast, the following variables were significantly correlated with a good prognosis: the performance of bronchoscopy during intubation $(\mathrm{OR}=0.25,95 \% \mathrm{Cl}$ 0.079-0.798; $p=0.019$ ), and the administration of co-trimoxazole (OR

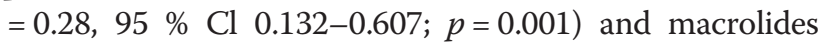
$(\mathrm{OR}=0.37,95 \% \mathrm{Cl} 0.155-0.867 ; p=0.022)$. The mortality rates of the patients who were treated in specialty and non-specialty hospitals did not differ to a statistically significant extent.

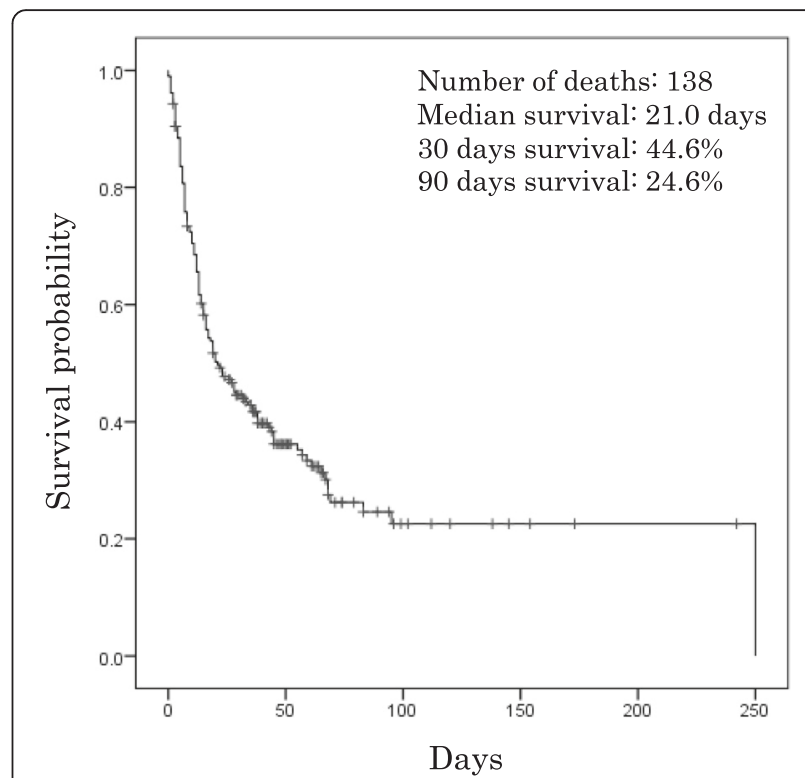

Fig. 2 Kaplan-Meier estimates of survival from the time of admission for all of the IPF patients

\section{The relationship between survival and co-trimoxazole dosage}

We examined the difference in the survival rates of patients who were treated with by co-trimoxazole tablets (sulfamethoxazole [400 mg] and trimethoprim [80 mg]) or the equivalent dose of co-trimoxazole granules and injections. Figure 4 represents the relationship between the survival rates of three groups of patients who were treated with different doses of co-trimoxazole. The doses were defined as follows: high dose (solid line; $\geq 6$ tablets daily, $n=74$ ), low dose (broken line; $1-5$ tablets daily, $n$ $=41$ ) and no co-trimoxazole (dotted line; $n=94)$. Cotrimoxazole treatment in the low-dose and high-dose groups was initiated an average of 7.9 and 8.3 days after admission, respectively. The survival of the patients in the high-dose group was significantly longer than that in the low-dose and no co-trimoxazole groups (log rank $p$ $<0.001)$. The survival of the patients in the low-dose group was also significantly longer than that in the no co-trimoxazole group (log rank $p=0.009)$ (Fig. 4).

\section{Discussion}

Thus far, there have been no large data sets on the prognosis and prognostic factors in IPF patients with rapid progression of respiratory failure. The data of the present study, which were extracted from a nation-wide Japanese epidemiological database show, for the first time, the current prognosis of IPF patients with rapid progression of respiratory failure who receive treatment with high-dose corticosteroids. Treatments with cotrimoxazole and macrolides were significantly associated 


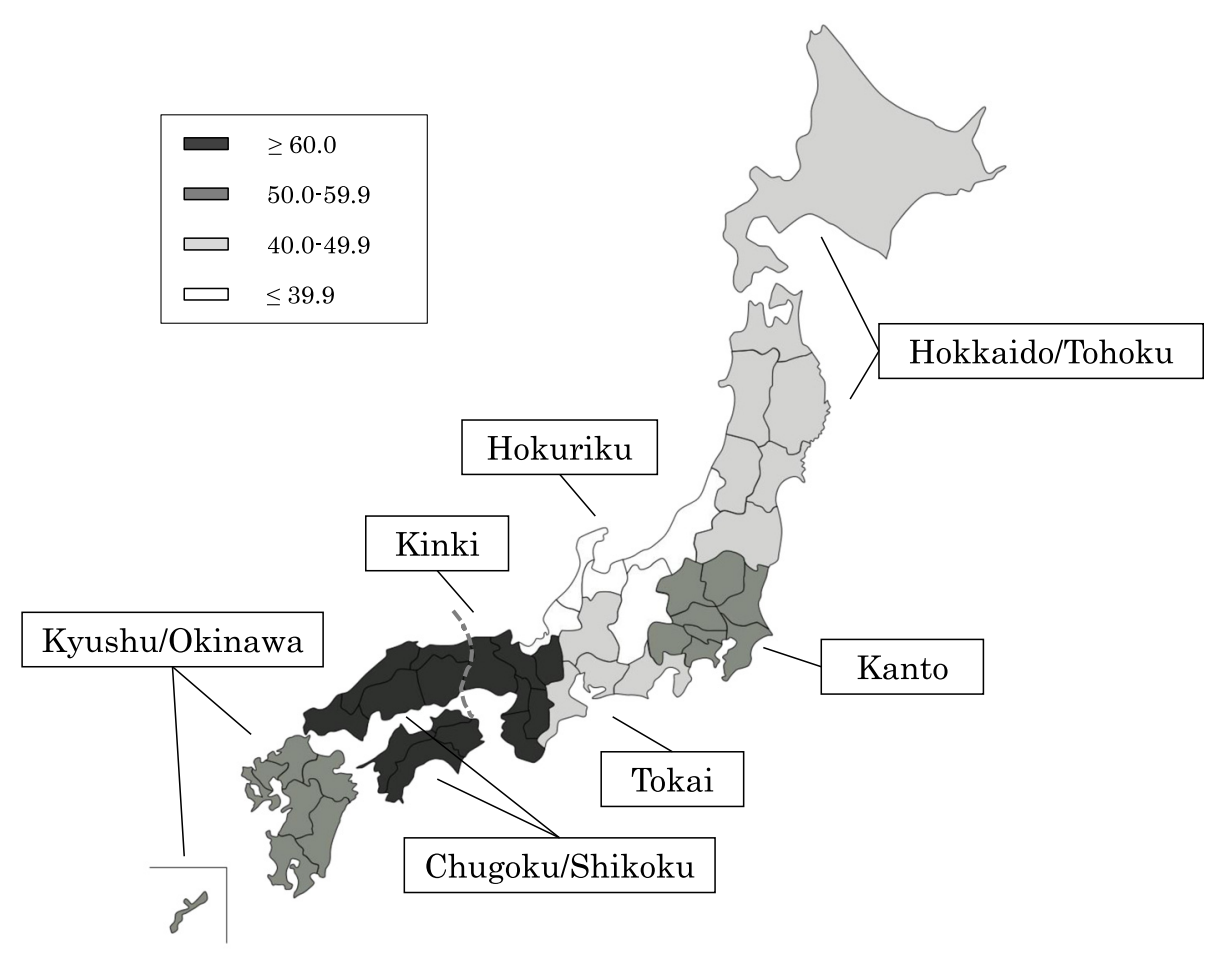

Fig. 3 The definition of the regions in Japan and short-term mortality

with a good prognosis and are considered to be effective when administered in combination with high-dose corticosteroids. The performance of bronchoscopy during ventilatory support was also correlated with a good prognosis. Conversely, the intravenous administration of high-dose cyclophosphamide was significantly associated with a poor prognosis. Our findings suggest that these managements may improve the morbidities associated with severe rapidly progressive of IPF.

Using a large, nationally representative Japanese database allowed us to investigate the prognostic factors for in-hospital mortality in IPF patients with rapid progression of respiratory failure. The application of mechanical ventilation in IPF patients with respiratory failure is considered to be a "weak" recommendation [2]. The 90-day mortality rate of patients with severe rapidly progressive IPF who received mechanical ventilation $(75.4 \%)$ was lower than the previously reported rate (approximately $90 \%)[5,15]$. Our results indicate that in such patients, the provision of mechanical ventilation may still be controversial. Similarly to stable patients with IPF [16], IPF patients who were older than 80 years of age showed a very poor prognosis in the present study. According to our data, ventilatory support may not be recommended in these patients. Similar to a previous report [17], a significantly higher number of patients were admitted due to IPF with rapid progression of respiratory failure in winter than in spring; however, there were no locationbased differences in Japan. In contrast with stable patients with IPF [18], no differences of mortality were observed according to whether or patients were admitted to specialty or non-specialty hospitals.

Although there have only been limited data on the role of bacterial infection in IPF patients, recent reports suggest the high importance of infectious causes and the importance of the progression of IPF $[19,20]$ in the development of AE-IPF [21]. In cases where the exclusion of infectious causes was insufficient (e.g. when they were diagnosed by the analysis of endotracheal aspirate or bronchoalveolar lavage fluid), they were considered as cases of suspected AE-IPF. It has been reported that the prognosis of patients with suspected AE-IPF is not significantly different to that of patients with definite AE-IPF [7]. The data in the present study showed that the performance of bronchoscopy might be related to a better prognosis (Table 3). The majority of AE-IPF patients received empiric antimicrobial treatments, which targeted common respiratory pathogens (although there has been no data to support their use in AE-IPF patients) [22]. The infectious causes of respiratory failure can easily missed, even when several microbiological tests are performed for clinical reasons: in the treatment of such patients it is not usually possible to wait for microbiological results, and antimicrobial treatments are 
Table 2 The comparison of the clinical features of survivors and the non-survivors

\begin{tabular}{|c|c|c|c|}
\hline & Survivors & Non-survivors & $p$-value \\
\hline Patients & 71 & 138 & \\
\hline Age, years & $69.3 \pm 10.2$ & $73.8 \pm 8.8$ & 0.002 \\
\hline Male & $56(78.9)$ & $116(84.1)$ & 0.352 \\
\hline $\mathrm{BMI}, \mathrm{kg} / \mathrm{m}^{2}$ & $22.2 \pm 3.9$ & $22.3 \pm 3.8$ & 0.795 \\
\hline \multicolumn{4}{|l|}{ Brinkman Index } \\
\hline $0 / 1-800 />800$ & $26 / 14 / 25$ & $42 / 31 / 46$ & 0.719 \\
\hline \multicolumn{4}{|l|}{ F, H-J Classification scale } \\
\hline $1 / 2 / 3 / 4 / 5$ & $1 / 3 / 3 / 16 / 42$ & $1 / 1 / 4 / 12 / 83$ & 0.012 \\
\hline Specialty hospital care & $60(84.5)$ & $113(81.9)$ & 0.634 \\
\hline Ambulance transfer & $32(45.1)$ & $69(50.0)$ & 0.499 \\
\hline Performing bronchoscopy & $14(19.7)$ & $6(4.4)$ & $<0.001$ \\
\hline \multicolumn{4}{|l|}{ Treatment regimen use } \\
\hline Sivelestat & $37(52.1)$ & $67(48.9)$ & 0.626 \\
\hline Diuretic drug & $37(52.1)$ & $65(47.1)$ & 0.492 \\
\hline Anticoagulant therapy & $37(52.1)$ & $50(36.2)$ & 0.027 \\
\hline Immunosuppressive therapy & $30(42.3)$ & $45(32.6)$ & 0.169 \\
\hline Intravenous high-dose cyclophosphamide & $9(12.7)$ & $23(16.7)$ & 0.448 \\
\hline PMX & $4(5.6)$ & $9(6.5)$ & 0.801 \\
\hline Recombinant human soluble thrombomodulin & $3(4.2)$ & $6(4.4)$ & 0.967 \\
\hline Antibiotic therapy & $71(100)$ & $135(97.8)$ & 0.211 \\
\hline$\beta$-Lactams & $60(84.5)$ & $116(84.1)$ & 0.933 \\
\hline Co-trimoxazole & $56(78.9)$ & $59(42.8)$ & $<0.001$ \\
\hline Quinolones & $38(53.5)$ & $65(47.1)$ & 0.379 \\
\hline Macrolides & $23(32.4)$ & $25(18.1)$ & 0.020 \\
\hline Tetracycline & $6(8.5)$ & $12(8.7)$ & 0.952 \\
\hline Anti-MRSA antibiotics & $6(8.5)$ & $11(7.8)$ & 0.904 \\
\hline Clindamycin & $3(4.2)$ & $2(1.5)$ & 0.214 \\
\hline Aminoglycoside & $2(2.8)$ & $1(0.7)$ & 0.228 \\
\hline Others & $5(7.0)$ & $7(5.1)$ & 0.562 \\
\hline
\end{tabular}

Data are presented as mean \pm SD or $n(\%)$, unless otherwise indicated. Definition of abbreviations: BMI = Body Mass Index, F, H-J = Fletcher, Hugh-Jones, PMX = Direct hemoperfusion with polymyxin B-immobilized fiber, MRSA = Methicillin-resistant Staphylococcus aureus. The total dose was not equal to 209 because there were missing values in the data file

considered to be low-risk. The results of the present study suggest that antibiotic treatments (other than cotrimoxazole and macrolides) may not contribute to the survival of AE-IPF patients with respiratory failure. This study also showed a trend towards poor survival in patients who were treated with immunosuppressants, especially intravenous high-dose cyclophosphamide. Currently, there is no strong evidence to support the use of immunosuppressants in AE-IPF patients with respiratory failure, and further studies will be needed to evaluate the role of immunosuppressants when they are administered in combination with high-dose corticosteroids.

Several reports have described the relationship between the prognosis of IPF patients and the administration of co-trimoxazole or macrolides. Shimizu et al. hypothesized that the specific role of co-trimoxazole was linked to a high prevalence of Pneumocystis jiroveci colonization among patients with stable IPF [23]. Shulgina et al. also reported that the addition of co-trimoxazole therapy to the standard treatment for stable patients with fibrotic idiopathic interstitial pneumonia resulted in improved quality of life and a reduction in mortality [24]. Huie et al. investigated the potential role of infection in the exacerbation of acute respiratory symptoms in patients with IPF [25] and showed P. jiroveci may be associated with the onset of AE-IPF. Our data indicated that the administration of co-trimoxazole mortality in IPF patients with rapid progression of respiratory failure, not only at the treatment 
Table 3 Prognostic factors for survival

\begin{tabular}{|c|c|c|c|c|c|c|c|}
\hline \multirow[t]{2}{*}{ Variable } & \multirow[b]{2}{*}{$N(\%)$} & \multicolumn{3}{|c|}{ Univariate logistic analysis } & \multicolumn{3}{|c|}{ Multivariate logistic analysis } \\
\hline & & $\mathrm{OR}$ & $95 \% \mathrm{Cl}$ & $p$-value & $\mathrm{OR}$ & $95 \% \mathrm{Cl}$ & $p$-value \\
\hline Age, years & 209 & & & & & & \\
\hline$<60$ & $17(8.1)$ & ref & & & ref & & \\
\hline $60-69$ & $52(24.9)$ & 1.12 & $0.374-3.362$ & 0.839 & & & \\
\hline $70-79$ & $98(46.9)$ & 1.83 & $0.647-5.196$ & 0.254 & & & \\
\hline$\geq 80$ & $42(20.1)$ & 3.78 & $1.110-12.858$ & 0.033 & 2.94 & $1.044-8.303$ & 0.041 \\
\hline Male & $172(82.3)$ & 1.41 & $0.681-2.930$ & 0.354 & & & \\
\hline $\mathrm{BMI}, \mathrm{kg} / \mathrm{m}^{2}$ & 178 & & & & & & \\
\hline$<18.5$ & $27(15.2)$ & ref & & & & & \\
\hline $18.5-25$ & $114(64.0)$ & 1.43 & $0.604-3.388$ & 0.415 & & & \\
\hline$>25$ & $37(20.8)$ & 1.13 & $0.409-3.117$ & 0.814 & & & \\
\hline Brinkman Index & 184 & & & & & & \\
\hline 0 & $68(37.0)$ & ref & & & & & \\
\hline $1-800$ & $45(24.5)$ & 1.37 & $0.617-3.046$ & 0.439 & & & \\
\hline$>800$ & $71(33.6)$ & 1.14 & $0.571-2.271$ & 0.712 & & & \\
\hline F, H-J Classification scale & 166 & & & & & & \\
\hline $1-4$ & $41(24.7)$ & ref & & & ref & & \\
\hline 5 & $125(75.3)$ & 2.53 & $1.229-5.187$ & 0.012 & 2.13 & $0.931-4.856$ & 0.073 \\
\hline Specialty hospital care & $173(82.8)$ & 0.83 & $0.382-1.799$ & 0.635 & & & \\
\hline Ambulance transfer & $101(48.3)$ & 1.22 & $0.686-2.164$ & & & & \\
\hline Performing bronchoscopy & $20(9.6)$ & 0.19 & $0.068-0.506$ & 0.001 & 0.25 & $0.079-0.798$ & 0.019 \\
\hline Sivelestat & $104(49.8)$ & 0.87 & $0.489-1.538$ & 0.626 & & & \\
\hline Diuretic drug & $102(48.8)$ & 0.82 & $0.461-1.451$ & 0.493 & & & \\
\hline Anticoagulant therapy & $87(41.6)$ & 0.52 & $0.292-0.933$ & 0.028 & & & \\
\hline Immunosuppressive therapy & $75(35.9)$ & 0.66 & $0.366-1.193$ & 0.17 & & & \\
\hline Intravenous high-dose cyclophosphamide & $32(15.3)$ & 1.38 & $0.601-3.160$ & 0.449 & 3.17 & $1.101-9.148$ & 0.033 \\
\hline PMX & $13(6.2)$ & 1.17 & $0.347-3.935$ & 0.801 & & & \\
\hline Recombinant human soluble thrombomodulin & $9(4.3)$ & 1.03 & $0.250-4.247$ & 0.967 & & & \\
\hline Antibiotic therapy & $206(98.6)$ & - & - & & & & \\
\hline$\beta$-Lactams & $176(84.2)$ & 0.97 & $0.440-2.126$ & 0.933 & & & \\
\hline Co-trimoxazole & $115(55.0)$ & 0.20 & $0.103-0.388$ & $<0.001$ & & 0.28 & $0.132-0.607$ \\
\hline Quinolones & $103(49.3)$ & 0.77 & $0.436-1.372$ & 0.38 & & & \\
\hline Macrolides & $48(23.0)$ & 0.46 & $0.239-0.893$ & 0.022 & & 0.37 & $0.155-0.867$ \\
\hline Tetracycline & $18(8.6)$ & 1.03 & $0.370-2.875$ & 0.952 & & & \\
\hline Anti-MRSA antibiotics & $17(8.1)$ & 0.94 & $0.332-2.651$ & 0.904 & & & \\
\hline Clindamycin & $5(2.4)$ & 0.33 & $0.054-2.042$ & 0.235 & & & \\
\hline Aminoglycoside & $3(1.4)$ & 0.25 & $0.022-2.826$ & 0.264 & & & \\
\hline Others & $12(5.7)$ & 0.71 & $0.216-2.307$ & 0.564 & & & \\
\hline
\end{tabular}

Data are presented as $\mathrm{n}(\%)$, unless otherwise indicated. Definition of abbreviations: $B M I$ body mass index, $F, H-J$ Fletcher, Hugh-Jones, $P M X$ Direct hemoperfusion with polymyxin B-immobilized fiber, MRSA Methicillin-resistant Staphylococcus aureus

dose for P. jiroveci but also at lower doses. This favorable effect of co-trimoxazole might, in addition to its antimicrobial activity against $P$. jiroveci, may be due to its antiinflammatory effect: co-trimoxazole might have reduced the neutrophil-derived oxidative stress [26]. Macrolides have also been reported to have anti-inflammatory effects $[27,28]$. Kawamura et al. reported that azithromycin was associated with improved outcomes in patients with acute exacerbation of chronic fibrosing interstitial pneumonia [29]. The administration of macrolides and co-trimoxazol 


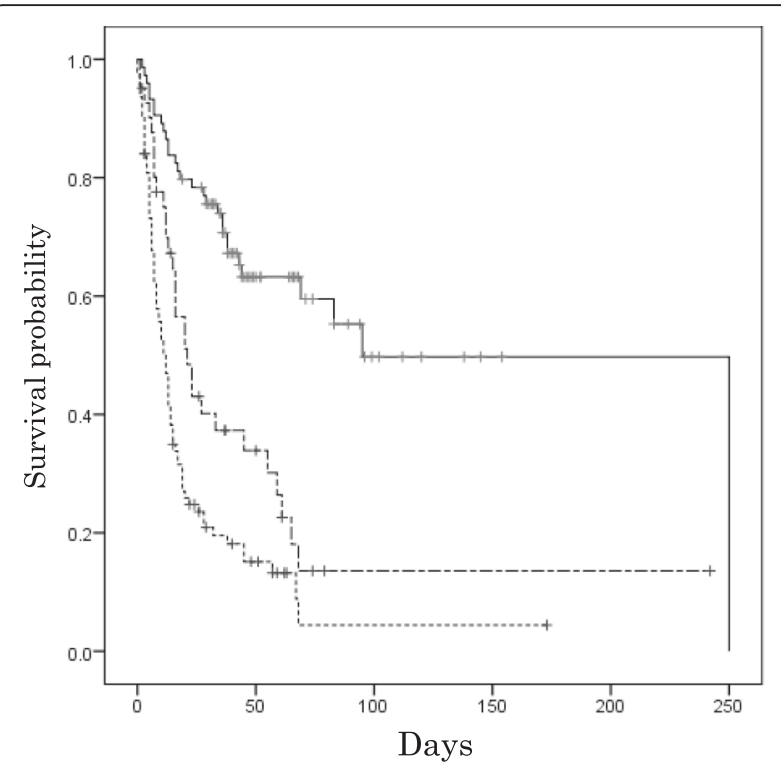

Fig. 4 Kaplan-Meier survival estimates according to the different doses of co-trimoxazole. A log-rank test revealed significant differences between all of the groups. High-dose (solid line, 74 patients), low-dose (broken line, 41 patients), none (dotted line, 94 patients)

may therefore increase the survival rate in patients with AE-IPF.

The present study is associated with several limitations. First, this study was a retrospective observational study. However, the analysis of the large data set of the DPC database system allowed us to perform our study in a large patient population. Tzilas et al. reported the weakness of the ICD coding system [30]; however, in addition to the ICD data our study also used the text data that were recorded in the DPC database system to clarify the physicians' diagnoses. Second, several clinical variables were not obtained, including the medication data and the patients' respiratory function before admission, and the results of bacteriological tests. However, we only enrolled IPF patients with rapid progression of respiratory failure in whom a ventilator was used on admission to ensure that the severity of IPF in our study population was uniform at the start of the observation period. Third, the DPC database system can only record in-hospital data, thus the data of the patients who were discharged from the DPC hospitals was not available and the contribution of their medications to survival may be underestimated. Finally, it is uncertain whether the regional clinical pathway would work the same way in other countries where health systems and policies differ from those in Japan. The effectiveness of the clinical pathway has been shown to be inconsistent in different areas and further studies are necessary to examine the applicability of this system to other countries.

\section{Conclusion}

We herein showed the epidemiology and prognosis of IPF patients with rapid progression of respiratory failure in recent years using a national administrative database in Japan. The performance of bronchoscopy during intubation, and the administration of co-trimoxazole and macrolides were significantly good prognostic factors. The concomitant use of co-trimoxazole in addition to high-dose corticosteroids may improve survival in IPF patients with rapid exacerbation of respiratory failure. Further clinical trials are necessary to verify the findings of the present study.

\section{Key messages}

- Rapid progression of respiratory failure in IPF patients was frequently seen in the winter. Older age and a higher grade of dyspnea on admission were poor prognostic factors. In addition, the prognosis of the patients did not differ in relation to the geographic area of Japan or in patients who were treated in a specialized hospital.

- The results of this study indicate that the prognosis of patients who underwent a bronchoscopic examination was better prognosis than those who did not; however, the performance of bronchoscopy in AE-IPF patients might be controversial.

- Regarding the treatment of IPF patients with rapid progression of respiratory failure, the use of high-dose corticosteroids in combination with macrolides and co-trimoxazole may lead to a better prognosis. However, prospective randomized controlled trials are necessary to elucidate the clinical effects of these agents.

\section{Abbreviations}

AE-IPF, Acute exacerbation of IPF; Cl, Confidence Intervals; DPC, Diagnosis Procedure Combination; F, H-J, Fletcher, Hugh-Jones; ICD-10, International Classification of Diseases and Related Health Problems, 10th Revision; IPF, Idiopathic Pulmonary Fibrosis; OR, Odds ratios

\section{Acknowledgements}

This research was partly supported by a grant to the Diffuse Lung Diseases Research Group from the Ministry of Health, Labour and Welfare, Japan and was a Ministry of Education, Science, Sports and Culture Grant-in-Aid for Scientific Research (B), 2013-2015 (25860665, Keishi Oda).

\section{Funding}

None.

Availability of data and materials

The dataset supporting the conclusions of this article is presented within the article. The detailed clinical data set is not publically available to protect research subject privacy and confidentiality.

\section{Authors' contributions}

$\mathrm{KO}$ and $\mathrm{KY}$ had full access to all the data in the study and takes responsibility for the integrity of the data and the accuracy of the data analysis. YF, KF, SM contributed to the data collection. $\mathrm{KY}$ and $\mathrm{HM}$ contributed to preparing the manuscript. T.H, T.O and T.K contributed to the design of the protocol. YF 
and HN contributed to the statistical data analysis. All authors read and approved the final manuscript.

\section{Competing interests}

The authors declare that they have no competing interests.

\section{Consent for publication}

Not applicable.

\section{Ethics approval and consent to participate}

This study was approved by the Ethics Committee of Tokyo Medical and Dental University, Tokyo, Japan (approval number 788).

\section{Author details}

'Department of Respiratory Medicine, University of Occupational and Environmental Health, Japan, 1-1, Iseigaoka, Yahatanishiku, Kitakyushu City, Fukuoka 807-8555, Japan. ²Department of Preventive Medicine and Community Health, University of Occupational and Environmental Health, Japan, 1-1, Iseigaoka, Yahatanishiku, Kitakyushu City, Fukuoka 807-8555, Japan. ${ }^{3}$ Miyazaki Prefectural Nursing University, 3-5-1 Manabino, Miyazaki city, Miyazaki 880-0929, Japan. ${ }^{4}$ Department of Health Care Informatics, Tokyo Medical and Dental University Graduate School, 1-5-45 Yushima, Bunkyoku, Tokyo 113-8510, Japan. ${ }^{5}$ Second Department of Internal Medicine, Nagasak University School of Medicine, 1-7-1 Sakamoto, Nagasaki 852-8501, Japan.

\section{Received: 25 November 2015 Accepted: 2 June 2016}

\section{Published online: 08 June 2016}

\section{References}

1. Natsuizaka M, Chiba H, Kuronuma K, Otsuka M, Kudo K, Mori M, Bando M, Sugiyama Y, Takahashi H. Epidemiologic survey of Japanese patients with idiopathic pulmonary fibrosis and investigation of ethnic differences. Am J Respir Crit Care Med. 2014;190(7):773-9.

2. Raghu G, Collard HR, Egan JJ, Martinez FJ, Behr J, Brown KK, Colby TV, Cordier JF, Flaherty KR, Lasky JA, et al. An official ATS/ERS/JRS/ALAT statement: idiopathic pulmonary fibrosis: evidence-based guidelines for diagnosis and management. Am J Respir Crit Care Med. 2011;183(6):788-824.

3. Kondoh Y, Taniguchi H, Kawabata Y, Yokoi T, Suzuki K, Takagi K. Acute exacerbation in idiopathic pulmonary fibrosis. Analysis of clinical and pathologic findings in three cases. Chest. 1993;103(6):1808-12.

4. Collard HR, Moore BB, Flaherty KR, Brown KK, Kaner RJ, King TE, Lasky JA, Loyd JE, Noth I, Olman MA, et al. Acute exacerbations of idiopathic pulmonary fibrosis. Am J Respir Crit Care Med. 2007:176(7):636-43.

5. Mallick S. Outcome of patients with idiopathic pulmonary fibrosis (IPF) ventilated in intensive care unit. Respir Med. 2008;102(10):1355-9.

6. Song JW, Hong SB, Lim CM, Koh Y, Kim DS. Acute exacerbation of idiopathic pulmonary fibrosis: incidence, risk factors and outcome. Eur Respir J. 2011;37(2):356-63.

7. Collard HR, Yow E, Richeldi L, Anstrom KJ, Glazer C, investigators I. Suspected acute exacerbation of idiopathic pulmonary fibrosis as an outcome measure in clinical trials. Respir Res. 2013;14:73.

8. Oda K, Ishimoto H, Yamada S, Kushima H, Ishii H, Imanaga T, Harada T, Ishimatsu Y, Matsumoto N, Naito K, et al. Autopsy analyses in acute exacerbation of idiopathic pulmonary fibrosis. Respir Res. 2014;15(1):109.

9. Juarez MM, Chan AL, Norris AG, Morrissey BM, Albertson TE. Acute exacerbation of idiopathic pulmonary fibrosis-a review of current and novel pharmacotherapies. J Thorac Dis. 2015;7(3):499-519.

10. Kataoka K, Taniguchi H, Kondoh Y, Nishiyama O, Kimura T, Matsuda T, Yokoyama T, Sakamoto K, Ando M. Recombinant human thrombomodulin in acute exacerbation of idiopathic pulmonary fibrosis. Chest 2015;148(2): 436-43.

11. Bhatti H, Girdhar A, Usman F, Cury J, Bajwa A. Approach to acute exacerbation of idiopathic pulmonary fibrosis. Ann Thorac Med. 2013;8(2):71-7.

12. Antoniou KM, Wells AU. Acute exacerbations of idiopathic pulmonary fibrosis. Respiration. 2013:86(4):265-74.

13. Kuwabara K, Matsuda S, Fushimi K, Ishikawa KB, Horiguchi H, Hayashida K, Fujimori K. Contribution of case-mix classification to profiling hospital characteristics and productivity. Int J Health Plann Manage. 2011;26(3):e138-50.

14. FLETCHER CM. The clinical diagnosis of pulmonary emphysema; an experimental study. Proc R Soc Med. 1952;45(9):577-84.
15. Gaudry S, Vincent F, Rabbat A, Nunes H, Crestani B, Naccache JM, Wolff M Thabut G, Valeyre D, Cohen Y, et al. Invasive mechanical ventilation in patients with fibrosing interstitial pneumonia. J Thorac Cardiovasc Surg. 2014;147(1):47-53.

16. Raghu G, Chen SY, Yeh WS, Maroni B, Li Q, Lee YC, Collard HR. Idiopathic pulmonary fibrosis in US Medicare beneficiaries aged 65 years and older: incidence, prevalence, and survival, 2001-11. Lancet Respir Med. 2014;2(7): 566-72.

17. Olson AL, Swigris JJ, Raghu G, Brown KK. Seasonal variation: mortality from pulmonary fibrosis is greatest in the winter. Chest. 2009;136(1):16-22.

18. Lamas DJ, Kawut SM, Bagiella E, Philip N, Arcasoy SM, Lederer DJ. Delayed access and survival in idiopathic pulmonary fibrosis: a cohort study. Am J Respir Crit Care Med. 2011;184(7):842-7.

19. Molyneaux PL, Cox MJ, Willis-Owen SA, Mallia P, Russell KE, Russell AM,

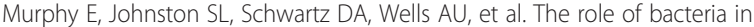
the pathogenesis and progression of idiopathic pulmonary fibrosis. Am J Respir Crit Care Med. 2014;190(8):906-13.

20. Han MK, Zhou Y, Murray S, Tayob N, Noth I, Lama VN, Moore BB, White ES, Flaherty KR, Huffnagle GB, et al. Lung microbiome and disease progression in idiopathic pulmonary fibrosis: an analysis of the COMET study. Lancet Respir Med. 2014;2(7):548-56.

21. Kim DS, Park JH, Park BK, Lee JS, Nicholson AG, Colby T. Acute exacerbation of idiopathic pulmonary fibrosis: frequency and clinical features. Eur Respir J. 2006:27(1):143-50

22. Collard HR, Loyd JE, King TE, Lancaster LH. Current diagnosis and management of idiopathic pulmonary fibrosis: a survey of academic physicians. Respir Med. 2007;101(9):2011-6.

23. Shimizu Y, Sunaga N, Dobashi K, Fueki M, Fueki N, Makino S, Mori M. Serum markers in interstitial pneumonia with and without Pneumocystis jirovecii colonization: a prospective study. BMC Infect Dis. 2009;9:47.

24. Shulgina L, Cahn AP, Chilvers ER, Parfrey H, Clark AB, Wilson EC, Twentyman OP, Davison AG, Curtin JJ, Crawford MB, et al. Treating idiopathic pulmonary fibrosis with the addition of co-trimoxazole: a randomised controlled trial. Thorax. 2013;68(2):155-62.

25. Huie TJ, Olson AL, Cosgrove GP, Janssen WJ, Lara AR, Lynch DA, Groshong SD, Moss M, Schwarz MI, Brown KK, et al. A detailed evaluation of acute respiratory decline in patients with fibrotic lung disease: aetiology and outcomes. Respirology. 2010;15(6):909-17.

26. Anderson R, Grabow G, Oosthuizen R, Theron A, Van Rensburg AJ. Effects of sulfamethoxazole and trimethoprim on human neutrophil and lymphocyte functions in vitro: in vivo effects of co-trimoxazole. Antimicrob Agents Chemother. 1980;17(3):322-6.

27. Kanoh S, Rubin BK. Mechanisms of action and clinical application of macrolides as immunomodulatory medications. Clin Microbiol Rev. 2010; 23(3):590-615

28. Ishimoto H, Mukae H, Sakamoto N, Amenomori M, Kitazaki T, Imamura Y, Fujita $H$, Ishii H, Nakayama S, Yanagihara K, et al. Different effects of telithromycin on MUC5AC production induced by human neutrophil peptide-1 or lipopolysaccharide in $\mathrm{NCl}-\mathrm{H} 292$ cells compared with azithromycin and clarithromycin. J Antimicrob Chemother. 2009:63(1):109-14.

29. Kawamura K, Ichikado K, Suga M, Yoshioka M. Efficacy of azithromycin for treatment of acute exacerbation of chronic fibrosing interstitial pneumonia: a prospective, open-label study with historical controls. Respiration. 2014; 87(6):478-84.

30. Tzilas $V$, Bouros $D$. Inherent weaknesses of the current ICD coding system regarding idiopathic pulmonary fibrosis. Eur Respir J. 2015;45(4):1194-6.

\section{Submit your next manuscript to BioMed Central} and we will help you at every step:

- We accept pre-submission inquiries

- Our selector tool helps you to find the most relevant journal

- We provide round the clock customer support

- Convenient online submission

- Thorough peer review

- Inclusion in PubMed and all major indexing services

- Maximum visibility for your research

Submit your manuscript at www.biomedcentral.com/submit 